\title{
Denickelification and Dezincification of Copper Alloys in Water Environments
}

\author{
Jun-Fu Liu, Mel J. Esmacher and David Kotwica
}

GE Power \& Water, Water \& Process Technologies, 9669 Grogans Mill Road, The Woodlands, TX 77380

Due to their high thermal conductivity, excellent ductility, and high resistance against corrosion, copper alloys are widely used in heat exchanger, tube, pipe fittings, and other components in water environments. However, de-alloying corrosion of copper alloys can occur in water environments, in which one or more elemental constituents are preferentially dissociated [1]. This presentation reports on denickelification and dezincification cases involving copper alloys.

To examine the failure of the copper alloy parts, optical microscopy and scanning electron microscopy (SEM) were used to acquire the surface morphology. Energy dispersive spectroscopy (EDS) was utilized to analyze the deposit and corrosion product composition.

Case 1 (Figure 1a) is a failed copper-nickel tube section (10\% $\mathrm{Ni}, 1 \% \mathrm{Fe}, 0.55 \% \mathrm{Mg}$, balance $\mathrm{Cu})$ from a heat exchanger. City make-up water circulating on the tube side was heated by a hot gas stream on the shell side of the exchanger. The time in service was 20 years. Purple deposits are observed at some locations on the internal surface (Figure 1b). SEM images in Figure 1(c, d) and EDS analysis in Figure le show that the purple deposits consist of $\mathrm{Cu}$ micro-crystals.

Case 2 (Figure 2a) is a silicon bronze pump impeller $(7.3 \% \mathrm{Zn}, 4.3 \% \mathrm{Si}$, balance $\mathrm{Cu}$ ) from a booster pump. The time in service in potable water was 2 years. In addition to erosion corrosion (Figure $2 \mathrm{a}$ ) due to excessive flow velocity and cavitation, surface dezincification of the bronze alloy resulted in localized red deposit area (Figure 2b). The SEM images in Figure 2(c, d) show that the area has a micro-porous surface texture. It is $99 \% \mathrm{Cu}$ from the EDS analysis result.

The de-alloying process is consistent with the mechanism of simultaneous dissolution of Ni (or $\mathrm{Zn}$ ) and $\mathrm{Cu}$, followed by re-deposition of $\mathrm{Cu}$.

$\mathrm{Ni}($ or $\mathrm{Zn}) \rightarrow \mathrm{Ni}^{2+}\left(\right.$ or $\left.\mathrm{Zn}^{2+}\right)+2 \mathrm{e}^{-}(\mathrm{Ni}$ or $\mathrm{Zn}$ oxidation $)$

$\mathrm{Cu} \rightarrow \mathrm{Cu}^{2+}+2 \mathrm{e}^{-}(\mathrm{Cu}$ oxidation $)$

Later $\mathrm{Cu}^{2+}$ ions were reduced to metallic $\mathrm{Cu}$ due to a higher tendency of $\mathrm{Cu}^{2+}$ than $\mathrm{Ni}^{2+}$ or $\mathrm{Zn}^{2+}$ ions to plate out of solution.

$\mathrm{Cu}^{2+}+2 \mathrm{e}^{-} \rightarrow \mathrm{Cu}(\mathrm{Cu}$ reduction $)$

References:

[1] S. Selvaraj et al, Corrosion Review 21 (2003), p. 41. 

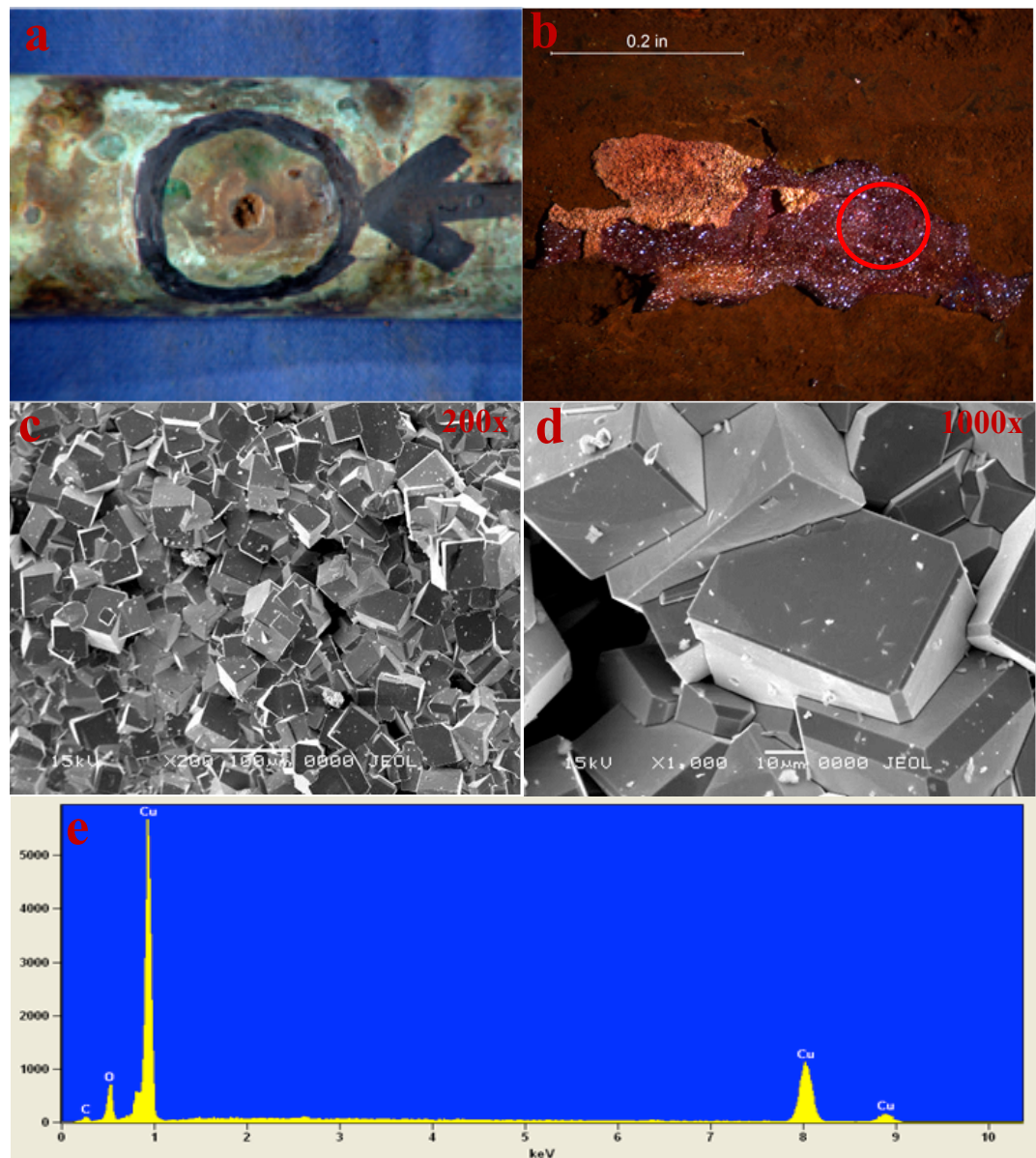

Figure 1. Photographs of (a) Ni-Cu tube and (b) purple deposit on the inside surface, and SEM images (c, d) of Cu micro-crystals of the purple deposit, and (e) EDS result.

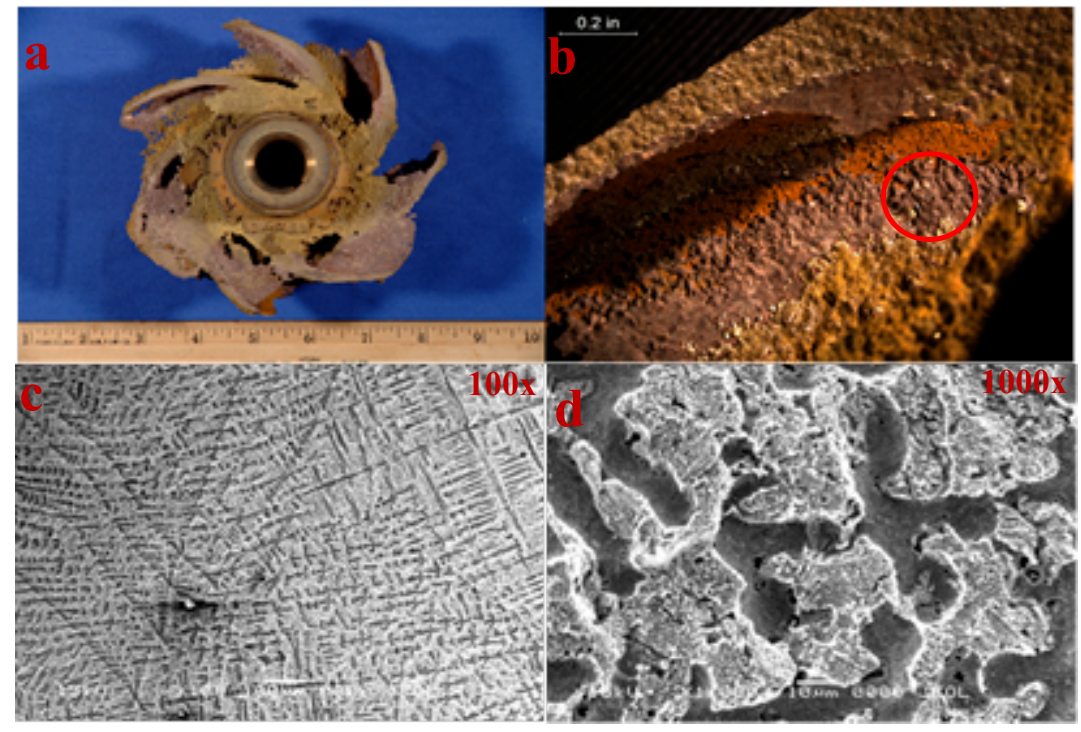

Figure 2. Photographs of (a) a silicon bronze pump impeller and (b) red deposit on the inside surface, and SEM images (c, d) of red $\mathrm{Cu}$ deposit area. 